
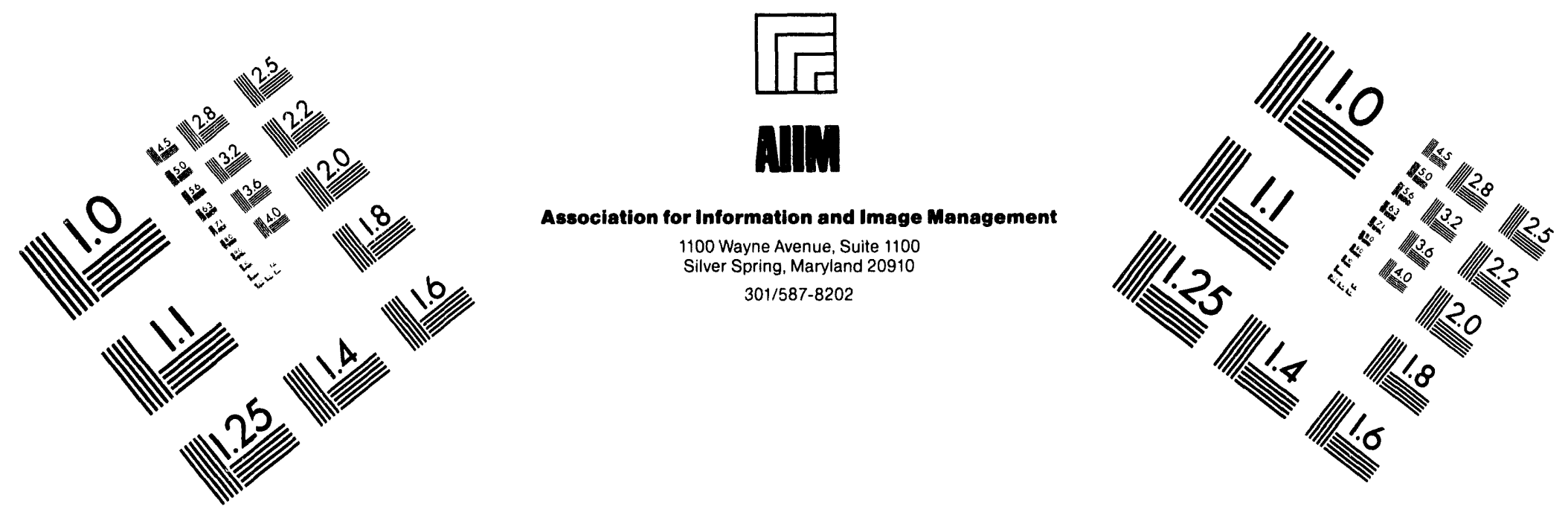

Centimeter

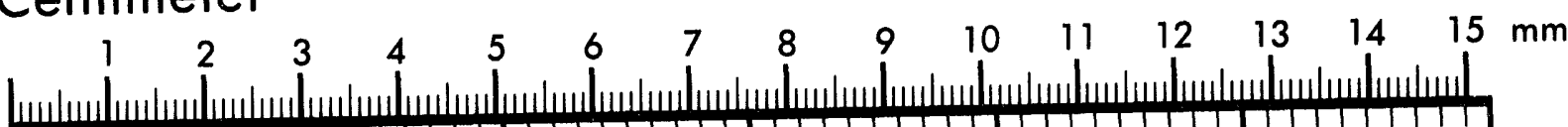

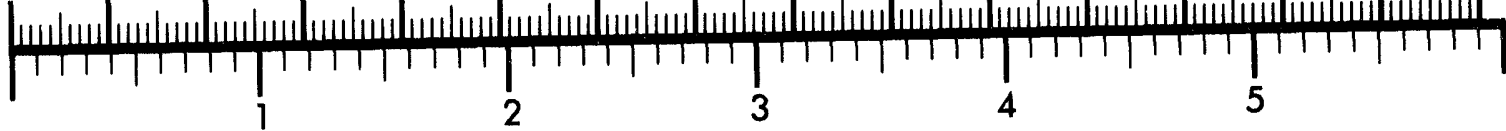
Inches
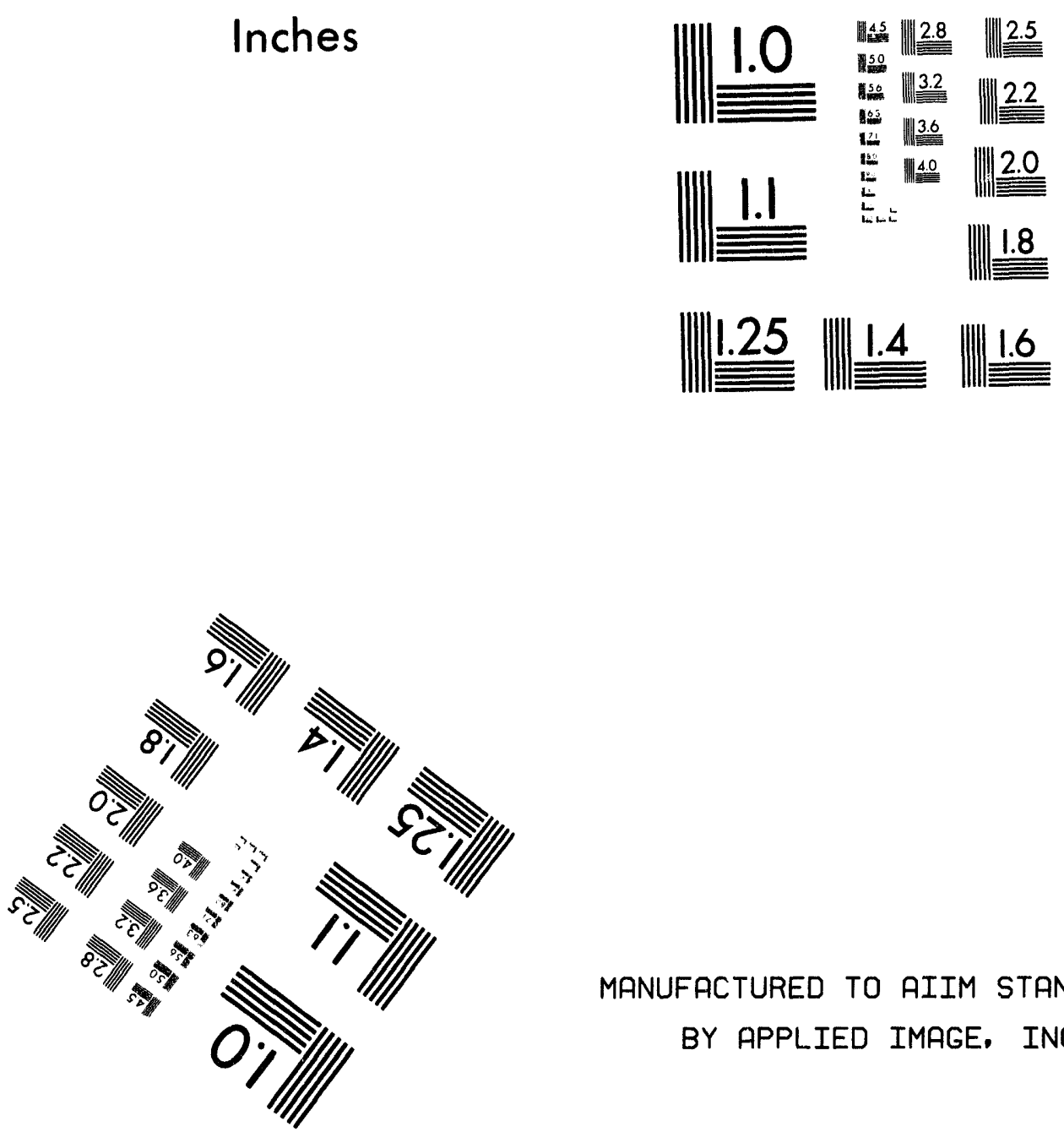

MANUFACTURED TO AIIM STANDARDS

BY APPLIED IMAGE, INC.

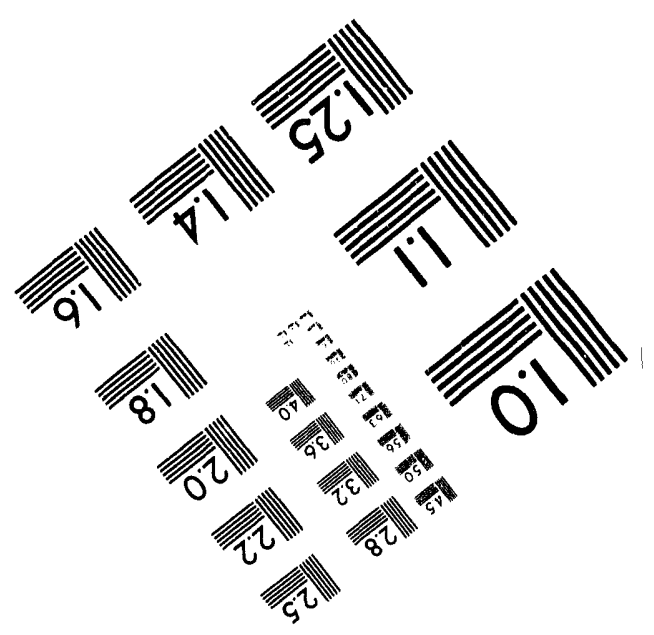



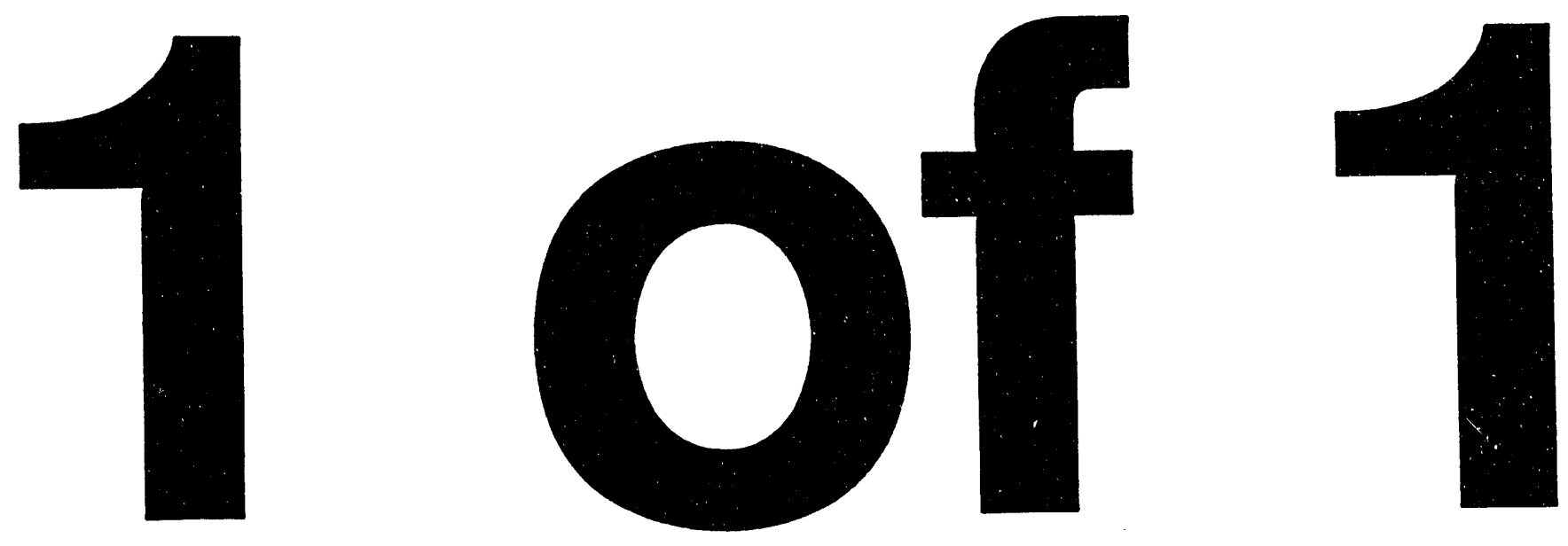


\title{
MSW TO HYDROGEN
}

\section{A. D. Pasternak, J. H. Richardson, R. S. Rogers, C. B. Thorsness, and H. Wallman \\ Lawrence Livermore National Laboratory Livermore, CA 94550}

\author{
G. N. Richter and J. K. Wolfenbarger \\ Montebello Research Laboratory \\ Texaco Inc \\ Montebello, CA 90640
}

\begin{abstract}
LLNL and Texaco are cooperatively developing a physical and chemical treatment method for the preparation and conversion of municipal solid waste (MSW) to hydrogen by gasification and purification. The laboratory focus will be on pretreatment of MSW waste in order to prepare a slurry of suitable viscosity and heating value to allow efficient and economical gasification and hydrogen production. Initial pretreatment approaches include 1) hydrothermal processing at saturated conditions around $300^{\circ} \mathrm{C}$ with or without chemical / $\mathrm{pH}$ modification and 2) mild dry pyrolysis with subsequent incorporation into an appropriate slurry. Initial experiments will be performed with newspaper, a major constituent of MSW, prior to actual work with progressively more representative MSW samples. Overall system modeling with special attention to energy efficiency and waste water handling of the pretreatment process will provide overall guidance to critical scale-up parameters. Incorporation of additional feed stock elements (e.g., heavy oil) will be evaluated subject to the heating value, viscosity, and economics of the MSW optimal slurry for hydrogen production. Ultimate scale-up of the optimized process will provide sufficient material for demonstration in the Texaco pilot facility; additional long term objectives include more detailed economic analysis of the process as a function of technical parameters and development of a measurement/control system to ensure slagging ash for variable MSW feed stocks. Details of the overall project plan and initial experimental and modeling results are presented.
\end{abstract}




\section{Introduction}

Municipal Solid Waste (MSW) is a large, growing, and little-used by-product resource of the United States. Approximately 200 million tons of MSW are produced annually in the United States, and the vast majority of this eventually winds up in landfills (Khan, 1993). Environmental concern over air pollution and the ash by-product has limited incineration as a disposal method, current landfills are becoming full, and concern over water pollution makes siting of future landfills difficult and expensive.

-.MSW is predominantly composed of carbon, hydrogen and oxygen, and as such is a potential" energy source. Thus, development of the technology necessary for gasification of MSW to hydrogen has the potential to address a number of economic, environmental, societal and resource issues. A path for the conversion of MSW to hydrogen has the potential to be economically advantageous because management and disposal of MSW is expensive, and the fees otherwise required to dispose of MSW become a credit against the cost of the produced hydrogen. The economics of MSW to hydrogen conversion relative to other sources will depend on tipping fees, the cost of alternate feed stocks such as coal or natural gas, and the differential processing costs. Conversion of MSW to hydrogen has the environmental advantage of decreasing the number of future landfills needed with the concomitant decrease in the associated water pollution issues. Furthermore, as gasification of MSW involves recycling of what is predominantly biomass, it introduces virtually no new carbon into the atmosphere. Finally, the energy content of one ton of MSW is comparable to a barrel of oil. Recovery of that energy through gasification would eliminate importing approximately 200 million barrels of oil, or $\approx 3-4 \mathrm{~B} \$$. Thus, even recovery of only a substantial fraction of the energy in MSW would have significant environmental and fiscal impact on the United States.

This report describes work intended to be done jointly between Lawrence Livermore National Laboratory (LLNL) and Texaco. The objective of this work is to capitalize on the proven gasifier technology developed and marketed by Texaco for the purpose of generating hydrogen from MSW. The primary technical problem is the pretreatment of MSW into a form suitable to use as a feed stock to the Texaco gasifier. LLNL will focus its efforts on the effects of MSW pretreatment on the heating value and viscosity properties of slurries suitable for injection into the gasifier. Supplemental feed stocks would be considered as needed (e.g., coal; heavy oils, which are of particular interest in Califormia). The scope of this project did not include initial MSW classification; hence and as appropriate, additional industrial partnerships in the realm of MSW classification would be explored in order to address as fully as possible all the technical and economic issues.

The Texaco gasifier has been successfully developed and commercially employed for gasification of coal, heavy oils, and petroleum coke with subsequent shift and hydrogen separation. The Texaco gasifier has many advantages: 1) oxygen can be utilized as the oxidant, resulting in no dilution and few nitrogen impurities; 2) hazardous metals are encapsulated in the slag; 3 ) the high temperatures insure the complete destruction of hazardous organics; 4) the Texaco gasifier represents proven technology. Texaco will perform laboratory gasification runs of MSW feed stocks prepared by LLNL during the initial phase of pretreatment parameters optimization. Texaco and LLNL will jointly perform a system analysis of the feed preparation/gasification process in order to allow process tradeoffs to be evaluated on an economic as well as a technical basis. Slagging is both a proven asset and potential issue with respect to gasification of MSW. Consequently, another goal of this project is the development of a measurement/control system to ensure slagging ash for variable MSW feeds. Finally, it is intended that the project will conclude with the demonstration of MSW slurrying and subsequent gasification at the pilot scale size. 
Subsequent work may deal with alternate biomass and waste feed stocks which potentially represent major energy resources; e.g., there are approximately 7 million tons of dry sewage sludge produced daily in the United States (Khan, 1993). MSW in particular and biomass/waste in general are predicted to have the greatest potential for annualized growth of electricity generation and displacement among renewable energy resources during the next 20 years (US Department of Energy, 1991). The development of technically and economically successful pretreatment processes for biomass wiste suitable for subsequent gasification and hydrogen separation will make a major contribution towards the realization of this major renewable resource.

\section{Discussion}

\section{Composition and Heating Value}

Table 1 summarizes the average composition of MSW in the United States (AIChE, 1994).

Table 1. Typlcal MSW by materlal (U.S. average)

Material Percentage by Weight

Paper \& paperboard

Glass

Ferrous metals

Aluminum

Plastics

Rubber \& leather

Textiles

Wood

Food wastes

Yard wastes

Other
37.5

6.7

6.3

1.4

8.3

2.4

2.8

6.3

6.7

$17.9^{*}$

3.7

* Yard waste constitutes $30 \%$ in California

This data is similar to that reported from earlier surveys (Khan, 1993). Consequently, the major component in MSW is derived from biomass and consists predominantly of cellulose-like material. Typical heating values of MSW range from 3,500 to nearly 6,000 Btu/pound. Reducing either the water content (i.e., increasing the solids loading) or decreasing the percentage of inert components will increase the heat content (Hecht, 1983). Refuse Derived Fuel (RDF) results when MSW is pretreated to remove some of the water and inert components while leaving the combustible components. Heating values for RDF of nearly 6,000 to over $8,000 \mathrm{Btu} /$ pound can be achieved, thus approaching the heating value of medium ranked coals. RDF is generally categorized as fluff or densified (e.g., powder or pellets), and is more homogeneous and has a longer "shelf life" than MSW (Alter, 1983). However, conventional RDF would not form a high solids slurry, and hence is not suitable for direct injection into the Texaco gasifier. Typical atomic compositions and heating values for previously characterized MSW and RDF are presented in Table 2 (Ferraro, 1988; and General Electric, 1976). 
Table 2. Atomic Percent Composition and Heating Values for Representative MSW and RDF

\begin{tabular}{|c|c|c|c|c|c|}
\hline & As Received & $\underset{\text { Dry }}{\text { MSW }}$ & Dry-Ash-Free & GE MSW & GE RDF \\
\hline $\begin{array}{l}\text { Moisture } \\
\text { Carbon } \\
\text { Oxygen } \\
\text { Hydrogen } \\
\text { Nitrogen } \\
\text { Chlorine } \\
\text { Sulfur } \\
\text { Ash }\end{array}$ & $\begin{array}{r}29.2 \\
32.2 \\
24.2 \\
4.2 \\
0.4 \\
0.1 \\
0.2 \\
9.5\end{array}$ & $\begin{array}{c}0 \\
45.5 \\
34.2 \\
5.93 \\
0.6 \\
0.14 \\
0.28 \\
13.4\end{array}$ & $\begin{array}{l}0 \\
52.5 \\
39.5 \\
6.85 \\
0.7 \\
0.16 \\
0.32 \\
0\end{array}$ & $\begin{array}{r}25 \\
26.2 \\
22.1 \\
3.5 \\
0.6 \\
0.1 \\
0.1 \\
22.5\end{array}$ & $\begin{array}{r}23.8 \\
33.1 \\
28.7 \\
4.5 \\
0.6 \\
0.1 \\
0.1 \\
9.2\end{array}$ \\
\hline $\begin{array}{l}\text { Heating value } \\
\text { (BTU/pound) }\end{array}$ & 5800 & 8230 & 9480 & 4700 & 5870 \\
\hline
\end{tabular}

For comparison, sewage sludge typically varies from a primary sludge value of $\approx 7000 \mathrm{BTU} /$ pound to $4000 \mathrm{BTU} /$ pound after biological treatment and formation of secondary sludge (Khan, 1993).

\section{Hydrothermal Treatment}

Initially two pretreatment methods were considered: 1) hydrothermal treatment (at steam saturated conditions around $300^{\circ} \mathrm{C}$ ) with and without chemical or $\mathrm{pH}$ modification and 2) mild dry pyrolysis. In each case pretreatment conditions were to be varied and the outcome evaluated primarily on the basis of the heating value and viscosity of the resulting aqueous slurry. Additional experiments involving kinetic measurements of starting material modification, rate and speciation of gas evolution, and effects of simultaneous mechanical agitation/shearing would be performed as appropriate. Because MSW is predominantly cellulose, initial experiments would be done with a primarily cellulose material: newspaper.

Initial efforts to form a slurry from newspaper material subjected to dry pyrolysis were not particularly successful. In contrast, initial experiments using hydrothermal treatment at temperatures up to $300^{\circ} \mathrm{C}$ of newspaper, cellulose or tissue paper did result in the formation of slurries with almost $50 \%$ solids loading (by weight). However, water:solid ratios of at least 2:1 were required for complete immersion of the solid in water during the pretreatment. Not surprisingly, and although the detailed chemistry has not been elucidated, the excess water is a reactant which results in a product being formed which is more amenable to slurrying than the product resulting from dry pyrolysis.

Additional factors and considerations also led to a preference being given to hydrothermal treatment versus dry pyrolysis. 1) Although several different gasifiers are being developed suitable for handling biomass with or without a supplemental feed stock line in order to boost the heating value (Feldmann, 1986; Larson, 1992; Litt, 1990), the Texaco gasifier is a proven technology which has enjoyed widespread commercialization (Robin et al, 1989 and 1993). The Texaco gasifier offers several advantages. It uses pure oxygen; hence, there is no nitrogen dilution of the produced synthesis gas. The slagging in the Texaco gasifier also provides an environmental advantage, as noncombustible inorganics are effectively encapsulated and hazardous organics are completely destroyed. This gasifier requires a liquid slurry as an input feed stock. Hydrothermal treatment integrates well 
with slurry feed gasifiers; only dewatering or concentrating of the treated MSW is required. Conversely, dry pyrolysis requires an initial drying step. Because of the high water content in MSW, this would be accompanied by a large energy penalty. 2) Reports of similar hydrothermal treatment of classified MSW do result in an aqueous slurry with solids loading of up to $42 \%$ by weight and with heating values of over 6,000 Btu/pound (Klosky, 1994). 3) Initial classification of MSW, ultimately to form a RDF, involves aqueous shredding, settling, and separations processing. Also called wet resource recuvciaj, this process is being prototyped at several facilities throughout the United States (e.g., San Leandro, CA and Reno, NV). It would be a natural integration step to incorporate hydrothermal treatment into the wet resource recovery process before the final RDF is dried and formed (Gugliamo, 1994; Klosky, 1994). 4) Hydrothermal treatment is well established in the pulp and paper industry. Consequently, the future focus of the experimental pretreatment processing will be on hydrothermal treatment.

Hydrothermal treatment of cellulose results in a carbonization of the starting materials, as represented by the following reaction (Schuhmacher et al, 1960):

$$
\left(\mathrm{C}_{6} \mathrm{H}_{10} \mathrm{O}_{5}\right)_{4} \Rightarrow \mathrm{C}_{21} \mathrm{H}_{16} \mathrm{O}_{2}+3 \mathrm{CO}_{2}+12 \mathrm{H}_{2} \mathrm{O}+1.19 \mathrm{MJ}
$$

The solid component of the products is $47 \%$ by weight of the starting cellulose. Table 3 represents the evolution of cellulose and wood into a more carbonaceous material as a function of processing temperature for a total of 3 hours processing (Schuhmacher et al, 1960).

Table 3. Carbonization of Cellulose and Wood After Processing for 3 Hours

\begin{tabular}{|c|c|c|c|c|}
\hline${ }^{\circ}{ }^{\circ} \mathrm{C}$ & $\begin{array}{c}\text { Cellulose } \\
\text { H/C }\end{array}$ & $\mathrm{O} / \mathrm{C}$ & $\begin{array}{l}\text { Wood } \\
\text { H/C }\end{array}$ & $\mathrm{O} / \mathrm{C}$ \\
\hline $\begin{array}{c}\text { Unreacted } \\
225 \\
275 \\
340 \\
360 \\
370 \\
390\end{array}$ & $\begin{array}{l}1.67 \\
1.67 \\
1.27 \\
0.75 \\
-. \\
0.69 \\
0.71\end{array}$ & $\begin{array}{l}0.83 \\
0.83 \\
0.55 \\
0.19 \\
-- \\
0.1 \\
0.073\end{array}$ & $\begin{array}{l}1.46 \\
0.8 \\
0.86 \\
0.72 \\
0.63 \\
-- \\
--\end{array}$ & $\begin{array}{l}0.65 \\
0.65 \\
0.19 \\
0.22 \\
0.077 \\
-- \\
--\end{array}$ \\
\hline
\end{tabular}

Assuming that MSW decomposes in the hydrothermal process to the same final solid product as cellulose (a reasonable assumption considering that cellulose is the dominant component of MSW, especially after preliminary classification), the following reaction, expressed on a per carbon basis, approximates the carbonization of MSW (using the average composition of Table 1 for Maine MSW/RDF):

$$
\mathrm{CH}_{1.57} \mathrm{O}_{0.56} \Rightarrow 0.97 \mathrm{CH}_{0.76} \mathrm{O}_{0.095}+0.03 \mathrm{CO}_{2}+0.41 \mathrm{H}_{2} \mathrm{O}+21.4 \mathrm{~kJ}
$$

This solid product, $61 \%$ by weight of the starting ash-free MSW, has an estimated heating value of $14,400 \mathrm{Btu} /$ pound; the dry Maine MSW carbonized product, now containing $20 \%$ ash by weight, would have a heating value of $11,500 \mathrm{Btu}$ /pound. Thus the hydrothermal treatment of MSW results in a solid product with a heating value comparable to a good coal (Probstein, 1982). For comparison, 
a similar hydrothermal treatment of MSW resulted in a solid product comprising $79 \%$ by weight of the starting material, including ash (Klosky, 1994).

\section{Process Modeling}

A rudimentary overall process model has been constructed using ASPEN PLUS (a commercial process simulator from Aspen Technology Inc.). Figure 1 summarizes the overall division of the process into discrete modules: pretreatment, gasification, quench, cleanup, shift and separation. This model was used to provide an initial evaluation of the overall process with respect to major technical and economic inputs and outputs (e.g., steam requirements, shift temperatures, operating pressure, primary heat exchanger requirements, oxygen input, water recycling, hydrogen production rates, waste gas and water rates, batch vs. continuous MSW pretreatment processing). Furthermore, without requiring proprietary details, this model is also sufficient, to a first approximation, to model the overall gasification/shift/separation process, and the interaction between the energy/material flows in the overall process and those associated with the pretreatment steps.

All of the modules will not be described in detail. However, Figure 2 illustrates the level of detail currently existing in the model for a continuous hydrothermal pretreatment. Provision is made for a recycled water stream as well as a small slipstream of waste water to control, if necessary, any buildup of problem constituents. One conclusion is, therefore, that given recycle of water as desirable in the pretreatment, there is no absolute need to limit considerations to systems where high solids loading in the slurry are present after and prior to MSW decomposition (e.g., in a batch mode with steam heating and the associated uncertainties of uniform heating). Figures 3 and 4 illustrate overall process material/energy/water requirements for a 1600 ton/day plant (typical of a large landfill site). From such an overall model the ability to balance downstream processing outputs with pretreatment inputs is apparent. For example, the steam generated in the shift reaction is approximately that required in the hydrothermal pretreatment. Similarly, the heating value of the fuel gas generated during the hydrogen separation process is approximately equivalent to the heating value required for the overall shift processing. Separation is done by a 3 stage pressure swing adsorption process (Katofsky, 1993). Figure 4 corresponds to the solids loading previously demonstrated for carbonization of MSW (Klosky, 1994); the viscosity for this slurry was $\approx 1000 \mathrm{cp}$, well within Texaco's gasifier experience.

Consideration of the overall process is necessary in order to understand requirements on the initial classification and hydrothermal treatment of MSW. For example, current shift catalysts require some sulfur in the feed stock. Ironically, MSW is generally of such low sulfur content that sulfur may need to be added for the high temperature shift stage, with removal of $\mathrm{H}_{2} \mathrm{~S}$ prior to the low temperature shift catalyst bed. The capability of the Texaco gasifier to accommodate a large variability in ash content (species as well as quantity) decreases the initial classification restrictions on MSW. The slag is relatively unleachable, hence providing additional environmental advantages and decreasing restrictions on type and quantities of impurities in the MSW inorganic components. The process model permits consideration of different delivery pressures of the produced hydrogen. Finally, halides are effectively converted to inorganic forms in the gasifier and removed in the water quench, thereby removing a potential requirement on the hydrothermal pretreatment.

Even this initial process model provides some economic insight into the overall viability of the conversion of MSW to hydrogen. For example, the process depicted in Figure 3 has a very large requirement for heat exchangers, particularly in the hydrothermal treatment module. Figure 5 illustrates the dependence on this heat exchanger area and the additional plant process heating and cooling requirements as a function of approach temperature. Figure 6 uses a standard ASPEN PLUS cost for heat exchangers to calculate a minimum in the amortized cost for heat exchangers as a function of approach temperature. However, additional process modeling is still required, both from 
an economic, technical, and environmental standpoint (e.g., ammonia as a waste stream needs to be considered, there is considerable swing in the cost of heat exchanger materials).

The overall goal of this project is the production of hydrogen from MSW using the Texaco gasifier. Consequently, this initial process model was used to evaluate the performance of the gasifier as a function of solids loading. Figure 7 illustrates the ratio of synthesis gas (carbon monoxide and hydrogen) $r$ - : Huced by the gasifier to oxygen input as a function of slurry concentration. Table 4 represents some preliminary estimates of selected operating costs for the gasification of MSW to produce hydrogen. The costs of hydrogen from coal and natural gas are taken from the literature (Katofsky, 1993).

Table 4. Selected Operating Costs for the Production of Hydrogen from MSW.

\begin{tabular}{lcc}
\hline & Unit Cost & $\$ / \mathrm{kmol}$ \\
\hline Hydrogen (coal) & $12 / \mathrm{GJ}$ & 3.07 \\
Hydrogen (NG) & $6.5 / \mathrm{GJ}$ & 1.86 \\
Dilute slurry w heat exchanger & & \\
Capital costs, $5000 \mathrm{~m}^{2}$ & & 0.02 \\
$10 \mathrm{MW}$ Heating & $3.0 / \mathrm{GJ}$ & 0.03 \\
$35 \mathrm{MW}$ Cooling & $1.3 / \mathrm{GJ}$ & 0.05 \\
& & \\
Dilute slurry w/o heat exchanger & & 0.60 \\
$200 \mathrm{MW}$ Heating & $3.0 / \mathrm{GJ}$ & 0.26 \\
$200 \mathrm{MW}$ Cooling & $1.3 / \mathrm{GJ}$ & 0.75 \\
Classification/shredding & $25 /$ tonne & 0.43 \\
Oxygen (12 kg/s) & $36 /$ tonne & 1.65 \\
Tipping (30 kg/s) & $55 /$ tonne & \\
"\$500/m², $20 \%$ amortization rate & & \\
\hline
\end{tabular}

The capital costs for the heat exchanger were obtained from estimates made by ASPEN PLUS cost module $\left(\$ 500 / \mathrm{m}^{2}\right)$ and probably represent a lower bound. Oxygen values reflect a dedicated plant, and the classification/shredding are taken from estimates: of RDF costs (Office of Technology Assessment, 1979) which have been brought forward to 1993 dollars. Tipping fees vary greatly within the United States, ranging from lows of approximately $\$ 20 /$ ton to highs of over \$100/ton; $\$ 55 /$ ton was a recently quoted average (Klosky, 1994). Obviously many components have not been estimated in Table 4 (e.g., the cost of the gasifier and downstream shift and separation). However, the avoidance cost, represented by the tipping fee, is a lange off-set against what might be potentially significant costs associated with MSW pretreatment, and it is certain that tipping fees are only going to increase. 


\section{Conclusions}

Preliminary experiments plus overall process considerations have led to the initial conclusion that hydrothermal treatment is preferable to dry hydrolysis for the pretreatment of MSW. An initial process model has been built consisting of six primary modules: pretreatment, gasification, quench, cleanup, shift and separation. This model has been used to estimate the overall gasifier performance as a function of the solids loading in the aqueous slurry feed stock. While by no means conclusive, the model indicates that production of hydrogen from MSW might be economically competitive with coal or natural gas derived hydrogen. The reason for this somewhat surprising result is the relatively large influence of tipping fees in comparison to the preliminary estimates of the major additional costs associated with MSW pretreatment (e.g., heat exchangers, initial classification). Additional factors need to be considered (e.g., autoclave equipment) and a much more refined economic analysis needs to be completed. However, the initial results support the idea that hydrothermal treatment of MSW and its subsequent gasification is supportable from a technical, economic, and environmental basis.

\section{Future Work}

As this project is in its very early stages, significant future work is planned. A series of laboratory scale experiments are planned over the next 6 months in order to optimize the hydrothermal treatment conditions necessary to produce a slurry suitable for injection into the Texaco gasifier. These experiments will be batch Parr bomb experiments, using newspaper as the initial material and varying the time, temperature and $\mathrm{pH}$. Viscosities and heating values will be measured; the viscosities will be correlated with measurements at Texaco on slurries previously successfully injected into the pilot gasifier. In addition, the chemical composition of the hydrothermal process gas and water will be characterized.

It is our intention to move quickly into providing sufficient material for laboratory-scale and then pilot scale gasifier experiments at the Montebello Research Laboratory. Texaco has a portable 6 ton/day hydrothermal treatment facility which can be modified and upgraded for these experiments. LLNL is discussing mutual collahoration with an upstream MSW classifier as well as a small business involved in carbonization and wet oxidation of MSW. Material from the 6 ton/day hydrothermal plant will be evaluated by Texaco using a laboratory-scale gasifier. Ultimately enough material will be produced, using optimized parameters based on the process modeling, heating value and viscosity, for the Montebello pilot facility. It is expected that this data will be the basis for the design of a 100 ton/day hydrothermal facility. The overall process facility and process model should be sufficiently robust to entertain alternate feed stocks, accomplishing hydrogen production and waste destruction from a multiplicity of sources (e.g., sewage sludge, biomass, energetic materials, fossil fuel co-feeds).

\section{Acknowledgements}

This work was performed under the auspices of the U. S. Department of Energy by Lawrence Livermore National Laboratory under contract No. W-7405-Eng-48. 


\section{References}

AIChE, 1994. Garbage- The Story of Waste Management and Recycling, American Institute of Chemical engineers, 345 East 47th Street, New York, N.Y. 10017.

Alter, H. 1983. Materivi! Recovery from Municipal Solid Waste. New York: Marcel Dekker.

Feldman, H. G., M. A. Paisley, and H. R. Appelbaum. 1986. Conversion of Forest Residues to a Methane-Rich Gas. Report Number PNL-5798-3 DE 86 008521, prepared for Pacific Northwest Laboratories by Battelle Columbus Laboratories, Columbus, Ohio.

Ferraro, F. A. 1988. Results of Emissions and Ash Testing at a Modern Refuse-Derived Fuel Plant. AIChE Symposium Series - Resource Recovery of Municipal Sold Wastes, 265 Vol 84. pg 36-43.

General Electric Company, 1975. Solid Waste Management Technology. New York: Van Nostrand Reinhold Company.

Gugliamo, J. 1994. Private communication. Biomass Systems, Inc wet resource recovery system is described in A Brief Description of the Newest Resource Recovery System, Resource Recovery Report Volume XVII, No. 7, June, 1992.

Hecht, N. 1983. Design Principles in Resource Recovery Engineering. Boston: Butterworth Publishers.

Katofsky, R. E. 1993. The Production of Fluid Fuels from Biomass. Princeton University/Center for Energy and Environmental Studies Report No. 279. Princeton, NJ.

Khan, M. R. 1993. Clean Energy from Waste and Coal. ACS Symposium Series 515. Washington, D.C.: American Chemical Society.

Klosky, M., N. Dickinson, and C. Anderson. 1994. Chlorine, Sulfur, and Soluble Slag Extraction with Energy Density Improvements of a MSW Slurry. in Proceedings of the 19th International Conference on Coal Utilization \& Fuel Systems, Clearwater, Florida.

Larson, E. D. and R. E. Katofsky. 1992. Production of Methanol and Hydrogen from Biomass. Princeton University/Center for Energy and Environmental Studies Report No. 271. Princeton, NJ.

Litt, R. D., M. A. Paisley, and T. L. Tewksbury. 1990. Experimental Development of a Multi-Solid Fluidized Bed Reactor Concept. Report Number DOE/MC/23293-2856, prepared for Morgantown Energy Technology Center by Battelle Columbus Laboratories, Columbus, Ohio.

Office of Technology Assessment, Congress of the United States. 1979. Volume I: Materials and Energy from Municipal Waste - Resource Recovery and Recycling from Municipal Solid Waste and Beverage Container Deposit Legislation.

Probstein, R. F. and R. E. Hicks, 1982. Synthetic Fuels. New York: McGraw-Hill.

Robin, A.M., Wu, C.M, and Kassman, J.S. 1989. Integration and Testing of Hot Desulfurization and Entrained-flow Gasification for Power Generation Systems., Phase I, Preliminary Report for Period Oct. 1, 1987 - Jan. 1, 1989, Volume I - Program Summary and PDU Operations. Montebello Research Laboratory, Texaco, prepared for Morgantown Energy Technology Center. 
Robin, A.M., Leininger, T.F., Davis, L.A., Junjg D.Y., Kassman, J.S., Lafferty, W.L., Stevenson, J.S., Wolfenbarger, J.K., Wu, C.M., and Yang, P.P. 1993. Integration and Testing of Hot Desulfurization and Entrained-flow Gasification for Power Generation Systems., Fianl Report, Volume I - Program Summary and Summary of PDU Operations and Process Economics for the Period January 1, 1991 - September 30, $1992 . \quad$ Montebello Research Laboratory, Texaco, prepared for Morgantown Energy Technology Center.

Schuhmacher, J.P., Hutjens, F.J. and van Krevelen. 1960. Chemical Structure and Properties of Coal $X X V$ - Studies of Artificial Coalification. Fuel, 14: 223.

US Department of Energy, 1991. Energy Information Administration/Annual Energy Outlook.

\section{Figure Captions}

Figure 1. Overall process block dlagram modeled by ASPEN PLUS, showing princlple modules with corresponding major materlal and energy inputs and outputs.

Figure 2. Detalled processing steps included in the hydrothermal pretreatment module for a contInuous MSW slurry reactor, with circa 15\% by welght sollds Input, circa $50 \%$ by welght output, recycling of the majority of the water, and assoclated energy inputs/outputs.

Figure 3. Overall process block dlagram for 1600 tons/day MSW (30 kg/s corresponding to $18.3 \mathrm{~kg} / \mathrm{s}$ dry ash free), $55 \%$ sollds slurry to gasifler, hydrothermal treatment at $275^{\circ} \mathrm{C}$ and 6.5 MPa, gasifler at $1300^{\circ} \mathrm{C}$ and $4 \mathrm{MPa}$.

Figure 4. Overall process block dlagram for 1600 tons/day MSW (30 kg/s corresponding to $18.3 \mathrm{~kg} / \mathrm{s}$ dry ash free), $42 \%$ solids slurry to gasifler, hydrothermal treatment at $275^{\circ} \mathrm{C}$ and $6.5 \mathrm{MPa}$, gasifler at $1300^{\circ} \mathrm{C}$ and $4 \mathrm{MPa}$.

Figure 5. Heating-cooling trade-offs as a function of approach temperature for the large pretreatment heat exchanger; as the approach temperature (temperature difference between the input of the coollng stream and the output of the counterflowing heating stream) Increases, the heat exchanger area decreases but the additional plant process heating and cooling requirements (MW) increase.

Figure 6. Economic trade-offs for the large pretreatment heat exchanger as a function of approach temperature; as the approach temperature (temperature difference between the Input of the cooling stream and the output of the counter flowing heating stream) Increases, the heat exchanger area decreases. At an average heat exchanger cost of $\$ 500 / \mathrm{m}^{2}$ (stainless steel, ASPEN PLUS estimate), the total cost consisting of $20 \%$ amortized heat exchanger capltal cost and additional heating/cooling costs goes through a minimum at an approach temperature between 35-45 C.

Figure 7. Estimated gasifler performance $\left(1300^{\circ} \mathrm{C}, 4 \mathrm{MPa}\right)$, as measured by produced synthesls gas per unit oxygen Input, and calculated slurry heating values as a function of solids loading of the slurry feed. 


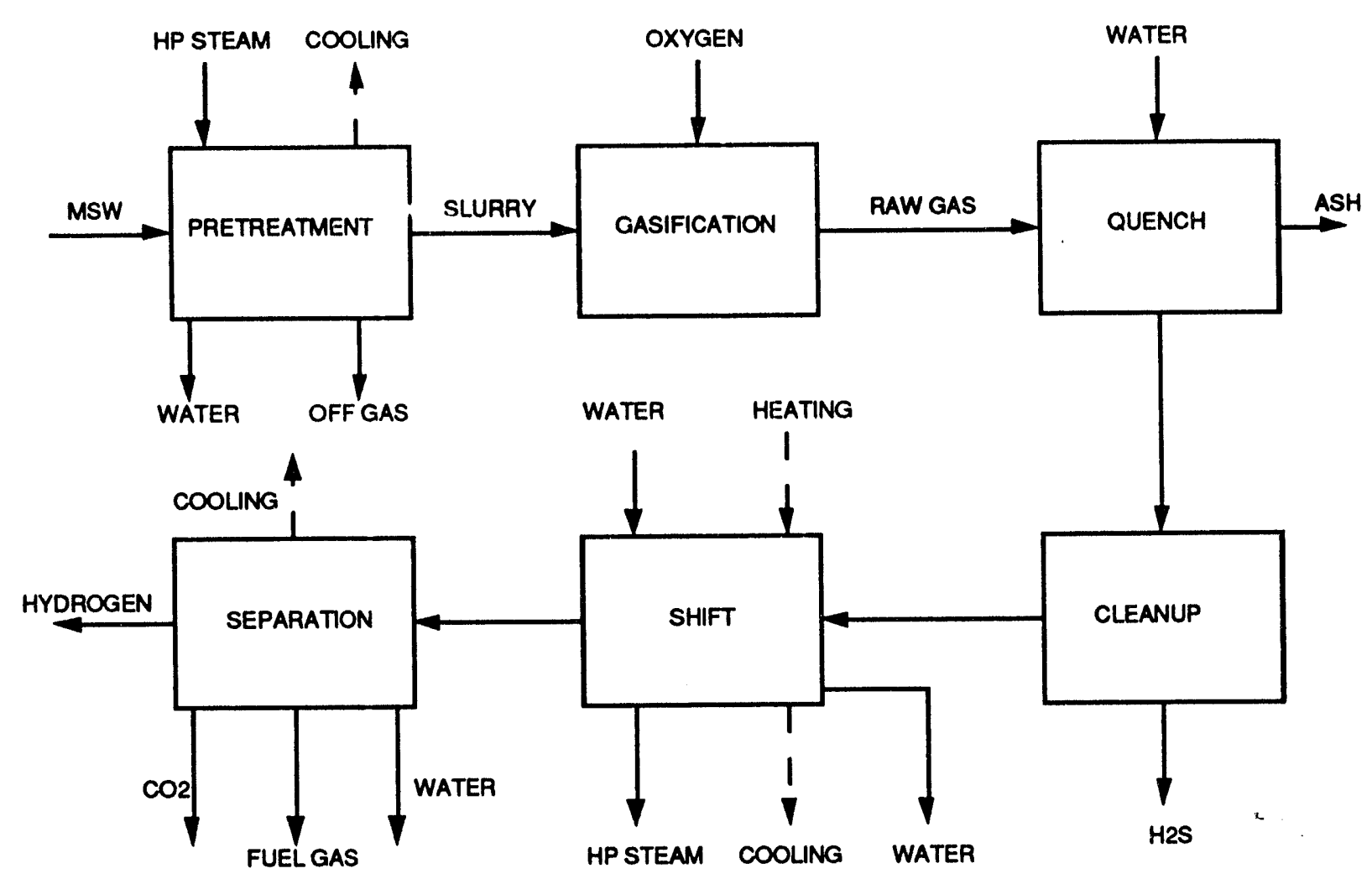




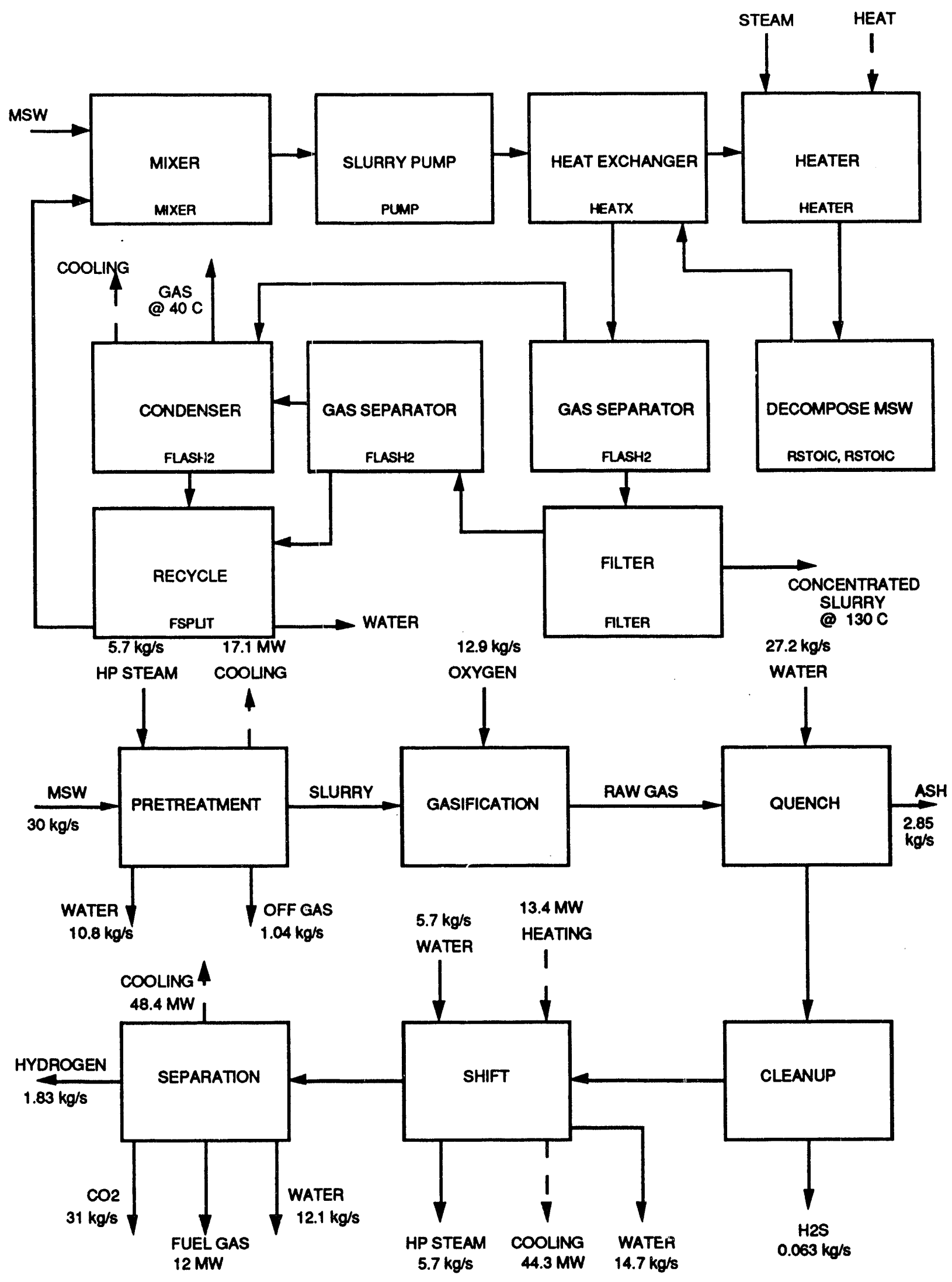




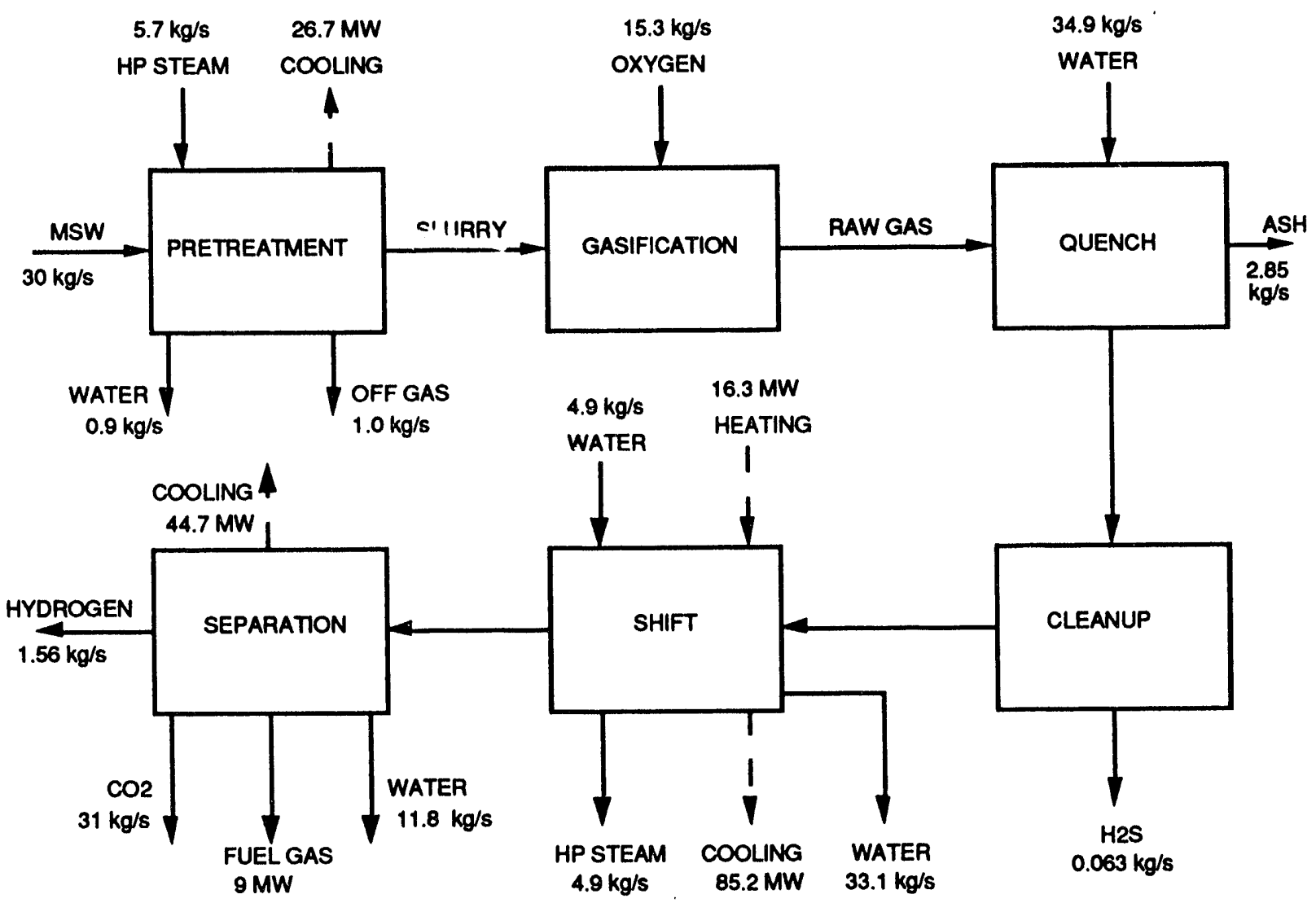




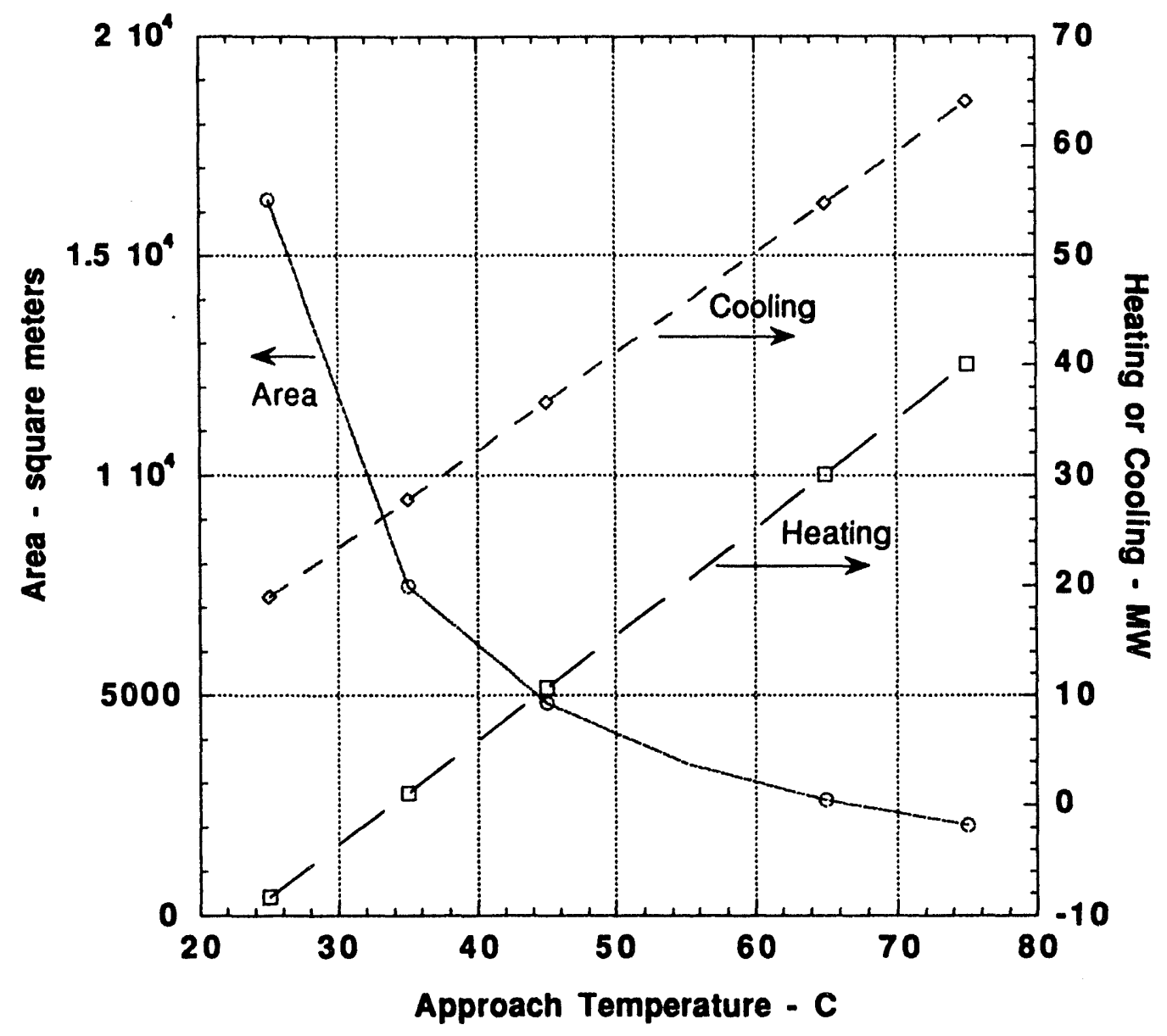




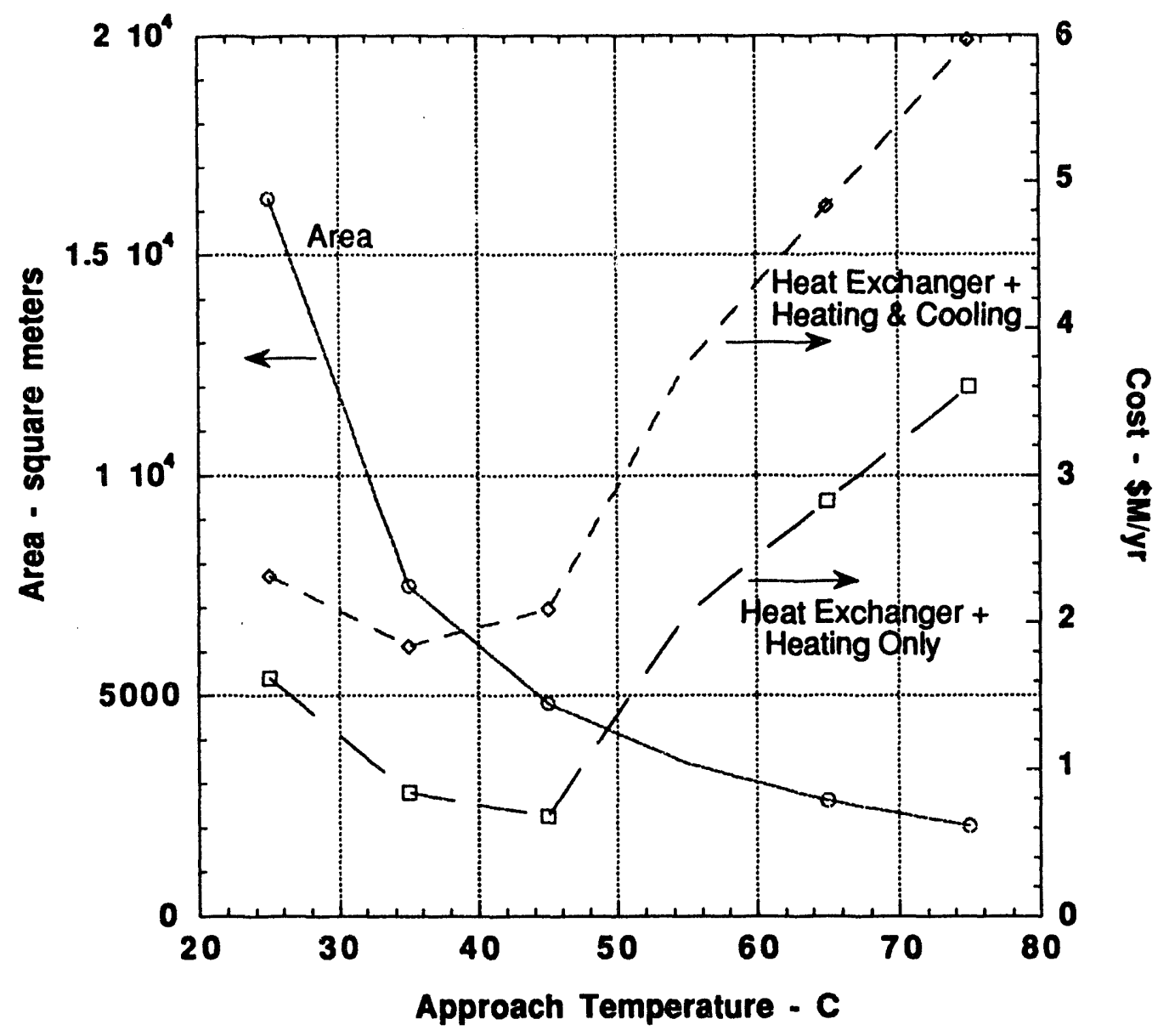




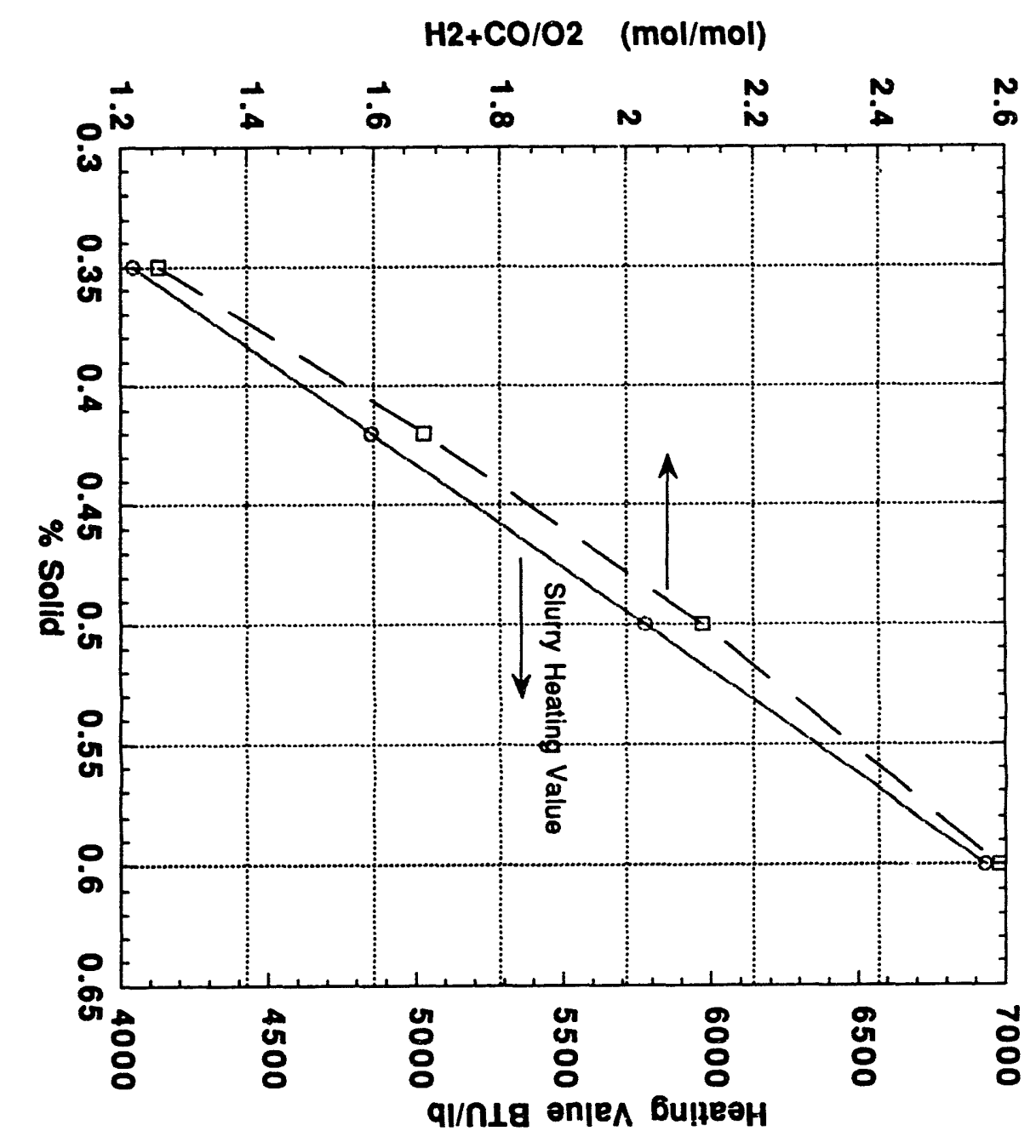



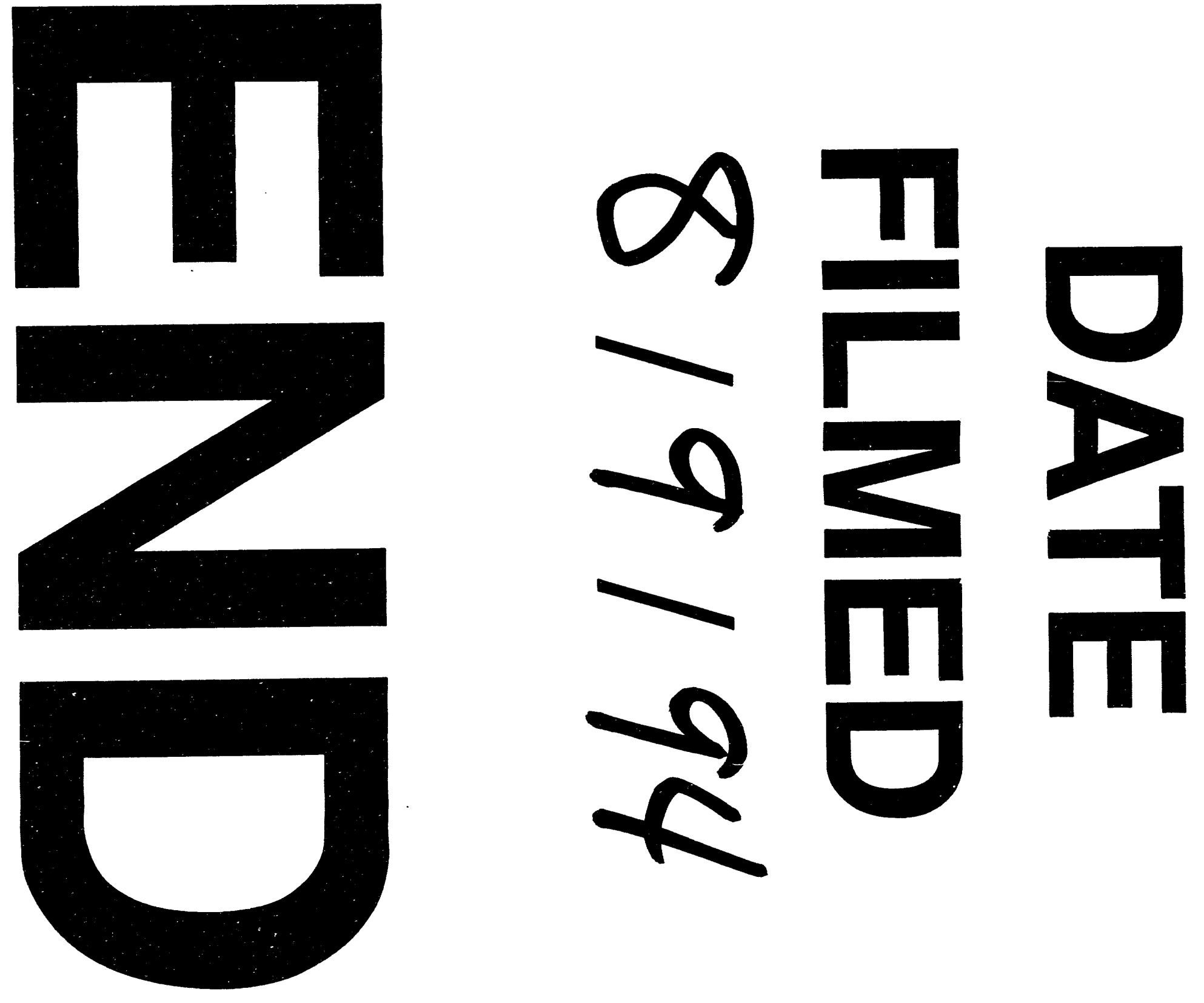
